\section{JIM}

ISSN: 2183-0606

(CC BY 3.0)

Vol. 9, $3(2021)$

p. $58-70$

AM: Jul/2021

SM: Nov/2020

\title{
The Balance of Cross-Functional Collaboration and Stretch and its Interaction with Firms' Innovation Performance
}

\author{
Wolfgang Gerstlberger ${ }^{1}$ and Alex da Mota Pedrosa ${ }^{2}$ \\ ${ }^{1}$ Department of Business Administration, Tallinn University of Technology, Ehitajate tee 5, 19086 \\ Tallinn, Estonia | wolfgang.gerstlberger@taltech.ee \\ ${ }^{2}$ Department of General Administration, Fachhochschule für Verwaltung und Dienstleistung, Rehmkamp \\ 10, 24161 Altenholz, Germany | pedrosa@fhvd-sh.de
}

\begin{abstract}
Literature does not provide a detailed explanation of the role of climate for innovation in the relationship between cross-functional collaboration and corporate innovation performance. The aim of this explorative study is therefore to investigate the complex interaction between cross-functional collaboration, climate for innovation and firms' innovation performance. Based on the analysis of a random data sample of heads of works councils of 450 large-sized firms in Germany, working with innovation, this paper finds, that there is an effect between cross-functional collaboration and innovation performance which is complementarily mediated by innovation climate. Overall, this finding leads to the conclusion that companies need to balance 'soft' factors as cross-functional collaboration and 'hard' factors as stretch in order to stimulate a productive innovation climate. Firms, which systematically work with and succeed in this balancing act, have also higher chances for increasing their innovation performance.
\end{abstract}

Keywords: Works Councils, Random Sample, Large-Sized Firms, Germany, Mediation Effect, Innovation Climate.

Cite paper as: Gerstlberger, W., Pedrosa, A.M., (2021). The Balance of Cross-Functional Collaboration and Stretch and its Interaction with Firms' Innovation Performance, Journal of Innovation Management, 9(3), 58-70.; DOI: https://doi.org/10.24840/2183-0606_009.003_0004

\section{Introduction}

Existing studies find a rather positive relationship between works council activities and firms' innovativeness. Potential explanations for this finding are, for example, strengthening cooperation and trust between management and staff or job enrichment for employees.

While the mentioned studies contribute to the understanding of the complex relations between work councils and management concerning innovation management in general, they neglect the detailed analysis of specific innovation practices on the firm and team level. More specifically, we still lack insights into the organizational 'channels' through which workplace codetermination influences firms' innovation performance. A supportive organizational climate for innovation and cross-functional collaboration seem to be two of these potential channels. However, the mechanisms of how organizational climate exactly influences firms' innovation performance remain unclear in existing studies (e.g., Whittall \& Trinczek, 2019; Johnston, 2020; Roy et al., 2020).

From a theoretical perspective, contingency theory might shed light on this area as it proposes that a company's performance depends on the match between its behaviour in fields such as 
cross-functional collaboration and specific internal conditions such as organizational climate (Atuahene-Gima \& Murray, 2007; de Luca \& Atuahene-Gima, 2007). As the interaction between cross-functional collaboration, organizational innovation climate and innovation performance is a very complex and firm-specific phenomenon, it requires tailored organizational approaches (Damanpour, 1996). In this context, it is often emphasized that cross-functional collaboration fosters the emergence of an organizational climate for innovation (e.g., González-Romá et al., 2002). This argument suggests that the climate for innovation mediates the effect of cross-functional collaboration on innovation performance.

Organizational context has similarities to the concepts of organizational culture, structural context, and organizational climate (Gibson \& Birkinshaw, 2004). Organizational culture refers to the underlying individual values, beliefs, and principles in organizations (Denison, 1990). Prior research describes organizational members' behaviour as practices and procedures that foster the development of a supportive organizational climate (e.g., González-Romá et al., 2002). Further, a supportive organizational climate is helpful for a firm's innovation performance as it encourages organizational members to feel responsible for their job and to develop alternative solutions for identified challenges (Baer \& Frese, 2003). In addition, in a supportive organizational climate organizational members are more inclined to accept challenging tasks (Bertels et al., 2011; Baer \& Frese, 2003; Scott, 1994; Patterson et al., 2005). Therefore, developing innovations benefits from a supportive innovation climate and, furthermore, collaboration across organizational members can help to align individual goals during innovation development (e.g., Atuahene-Gima \& Murray, 2007).

Furthermore, firms need a certain level of task-related stretch to push their employees for ambitious goals (Ghoshal \& Bartlett, 1994; de Vasconcelos et al., 2019). In this sense, stretch can be an element that supports cross-functional collaboration and therefore enhances the climate for innovation. However, there is a research gap in the literature on workplace codetermination and innovation management regarding the role of a supportive climate for innovation in the relationships between cross-functional collaboration, task-related stretch and innovation performance. Thus, the aim of this paper is to investigate the complex relationship between cross-functional collaboration, organizational climate for innovation, and innovation performance. More in detail, this study analyzes the following research question:

How is cross-functional collaboration related to a firm's climate for innovation and innovation performance?

Our study focused on heads of works councils in large-sized German firms because of their special role in German companies due to which they codetermine the company's innovation process and monitor those labour agreements are met (Whittall \& Trinczek, 2019; Genz et al., 2019; Kuhlenkötter et al., 2020). Further, heads of works councils can push through cross-functional collaboration on the strategic firm and operative project level for certain innovations that might lead to new jobs. We investigated, therefore, cross-functional collaboration and innovation climate as well as innovation performance in the perception of heads of works councils on the firm level.

\section{Literature Review and Hypotheses Development}

Cross-functional collaboration refers to the degree of collaboration among members of different departments of an organization during the innovation development process (Song et al., 1997; de Luca \& Atuahene-Gima, 2007). In the context of this paper, which focuses on heads of German works councils, cross-functional collaboration can refer to the project as well as to the firm level (Müller-Jentsch, 1995). On the firm level, the heads of large-sized firms in Germany are very often 
involved in committees or working groups which discuss and prepare strategic questions concerning their firms' innovation management together with top management members. Heads of works councils especially participate in such strategic meetings when general topics related to major changes of the number of staffs, work and incentive schedules or training activities are affected (Pries, 2006; Jirjahn, 2010). Furthermore, heads of works councils regularly participate in more operative innovation activities on the project level. Such project participation of works councils is, in many cases dedicated to specific changes in employment or working conditions in the whole firm or single departments due to innovation activities (Gumbrell-McCormick \& Hyman, 2010).

In general, cross-functional collaboration is structured and reflected by the degree of interdependence and interaction among organizational members during a collective task which they perform (Ernst et al., 2010). Therefore, cross-functional collaboration ensures the alignment of goals among organizational members during innovation development (de Luca \& Atuahene-Gima 2007; Ernst et al., 2010; Tsai \& Hsu 2014). Successful innovation development requires the exchange of diverse knowledge to enable organizational members to perform a wide set of tasks. However, organizational members are often exposed to conflicting and ambiguous information relevant for innovation development, for example, formal practices versus enacted practices (e.g., Zohar \& Tenne-Gazit, 2008). Such contradictory information demands collaboration among organizational members to develop a shared understanding or collective mind (Crossan et al., 1999; Weick \& Roberts, 1993), which is needed when developing innovations. More specifically, through collaborative activities, organizational members communicate and discuss their meanings to work activities, such as innovation development, and develop a shared interpretation of the organizational environment (Ashforth, 1985; Roberson, 2006). From this perspective, prior research shows that collaboration among different organizational members fosters the emergence of a supportive organizational climate, as a climate for innovation. Some studies have highlighted a positive relationship between interaction among organizational members and the organizational climate (e.g., Klein et al., 2001; González-Roma et al., 2002; Patterson et al., 2005). Thus, crossfunctional collaboration should be positively related to the organizational climate for innovation. (Ernst et al., 2010; de Vasconcelos et al., 2019). Furthermore, increased effort investment in dealing with challenging tasks as the development of innovations can result in greater innovation performance of an organization (Baer \& Frese, 2003; Scott, 1994). The reason for this relation is that a positive climate for innovation enhances organizational members' willingness to dedicate time and share resources while collaboratively developing innovations (Somech \& Drach-Zahavy, 2013). Therefore, the climate for innovation mediates the relationship between cross-functional collaboration and innovation performance.

H1: Cross-functional collaboration is positively related to a firm's climate for innovation.

H2: The effect of cross-functional collaboration on innovation performance is mediated by the firm's climate for innovation.

Finally, our model suggests that cross-functional collaboration enhances the climate for innovation, through the intervening variable of organizational stretch. This effect may be conditional on the moderator variable of organizational stretch for the path from cross-functional collaboration on climate for innovation.

Organizational stretch refers to an organizational characteristic that induces organizational members to voluntarily strive for more, rather than for less ambiguous goals (Gibson \& Birkinshaw, 2004, Vasconcelos Gomes et al., 2019). Organizations that foster stretch encourage organizational members to push for ambitious goals, as developing innovations might be (Ghoshal \& Barlett, 1994). This sense of aiming for ambitious goals guides organizational members during the innovation development process. When the organizational stretch is silent, organizational members 
use development teams' goals, norms, and values in regulating their behaviour (Ashford et al., 2008; Jasmand et al., 2012). Such consensus reduces the range of means that might be used to attain goals. Organizational members then reduce the active consideration of other possibilities while striving for ambitious goals. While organizational stretch enhances the continuous striving for more, it purposefully guides cross-functional collaboration resulting in a greater climate for innovation which in turn will promote organizational innovation performance. Accordingly:

H3: The indirect effect of cross-functional collaboration on innovation performance through firm's innovation climate is moderated by stretch.

\section{Methodology}

We collected the data through an online survey across a random sample of 450 large-sized companies located in Germany. In the context of this paper, we focus on large-sized firms because larger companies in Germany systematically engage in innovation activities and consequently support innovations (e.g. Berlemann \& Jahn, 2014). Further, larger-sized companies are covered to a much higher degree by works councils than smaller firms, as in German companies (with at least five employees) the initiation of works councils depends on employees' decisions and activities.

To the extent possible, the questions used in the survey were based on innovation management, human resources management, and organizational design literature. The developed survey was presented and discussed with academics knowledgeable in the research area; as a result, some questions were revised to improve their clarity. Afterwards, 25 appointments with the head of works councils were scheduled to pre-test the survey. On the basis of their feedback, we identified ambiguities and unclear questions and eliminated or shorted several items. We administered the survey to 450 companies located in Germany that have a works council. We guaranteed confidential and anonymous treatment of the responses for the survey. After three reminders, a total of 211 companies had responded to the survey. This equals a response rate of $46.8 \%$. However, because of missing values, only 200 responses were used for the analysis. Only heads of works' councils responded to the online survey. In most of the large-sized firms in our sample, the heads of the works councils are released from their original work activities and can focus full-time on their tasks as elected employee representatives (Gumbrell-McCormick \& Hyman, 2010). Due to this privilege, they can regularly participate in cross-functional collaboration, both on firm and project levels. Based on the intensity of such managerial and strategic and project activities, heads of German works councils can be characterized as 'cross-departmental members of the middle management of their firms (Kuhlenkötter et al., 2020; Bosch \& Schmitz-Kießler, 2020; Nienhüser, 2020). The 198 companies included in the data set have an average of 606 employees. Further, the companies operate in industries such as transportation, financial services, retailing, and machinery.

To rule out systematic effects on our data and hypothesis testing, we tested for selection and nonresponse bias by comparing early and late respondents on our key variables and firm characteristics. None of these comparisons revealed significant differences. To minimize common method variance, we followed the suggestions of Podsakoff et al. (2003). We psychologically separated the measures of the independent variables from those of the proposed mediators and dependent variables by placing them into different thematic sections in the questionnaire, such that they appeared unrelated. In addition, Harman's one-factor test on all items did not reveal a single factor accounting for most of the covariance in the variables, suggesting that common method bias is not present in this study. 
To measure our study constructs, we relied on established scales and adapted them where necessary. For the innovation climate, 7 items adapted from Scott (1994) were used. Based on Müller-Jentsch (1998) we measured cross-functional collaboration with 5 items that reflected the extent of cooperation within the firm. For example, we asked the respondents to rate the extent to which employees from different departments are fully cooperated in establishing goals and priorities for the company's strategy. On the basis of the study of Gibson and Birkinshaw (2004), we measured stretch with 3 items. The items asked respondents to indicate the extent to which their company encourages organizational members to set challenging goals and to strive for more. Finally, Song and Perry (1997) informed the measure of innovation performance. As our outcome variable was measured on the company level, we included relevant company-level control variables in our analysis. First, we included a dummy variable representing the number of full-time employees provided by the employment office. Second, we included a dummy variable representing whether each company was offering products or services.

Before we started our data analysis, we carefully checked among our continuous variables for univariate outliers by inspecting the standardized scores (measures with a z score in excess of \pm 3 ) and the normal probability plots. Since we did not detect any outliers, we did not exclude any further cases.

\section{Results}

Table 1 provides a summary of the correlation matrix, descriptive statistics, and Cronbach's alpha values for the performed statistical calculations.

Table 1. Descriptive statistics.

\begin{tabular}{lccccccccc}
\hline & $\mathbf{M}$ & SD & $\alpha$ & $\mathbf{1}$ & $\mathbf{2}$ & $\mathbf{3}$ & $\mathbf{4}$ & $\mathbf{5}$ & $\mathbf{6}$ \\
\hline $\begin{array}{l}\text { 1. Innovation } \\
\text { performance }\end{array}$ & 5.17 & 1.21 & .803 & 1.0 & & & & \\
\hline $\begin{array}{l}\text { 2. Climate for } \\
\text { innovation }\end{array}$ & 4.09 & 1.25 & .901 & $.49^{* *}$ & 1.0 & & & \\
\hline $\begin{array}{l}\text { 3. Cross-functional } \\
\text { collaboration }\end{array}$ & 4.05 & 1.27 & .819 & $.42^{* *}$ & $.49^{* *}$ & 1.0 & & \\
\hline $\begin{array}{l}\text { 4. Stretch } \\
\text { 5. Industry sector }\end{array}$ & 5.13 & 1.26 & .848 & $.36^{* *}$ & $.57^{* *}$ & $.45^{* *}$ & 1.0 & \\
\hline $\begin{array}{l}\text { 6. Number of } \\
\text { employees }\end{array}$ & 606.1 & 773.22 & N.A. & .02 & .07 & .03 & .11 & $-17^{*}$ & 1.0 \\
$\begin{array}{l}* \mathrm{p}<.05 \text { (two-tailed); } \\
\text { ** } \mathrm{p}<.01 \text { (two-tailed) }\end{array}$ & & & & & & & \\
\hline
\end{tabular}

The theoretical model (cf. figure 1) of our study implies a moderated mediation model (Hayes, 2015; Preacher et al., 2007), in which the relationship between cross-functional collaboration and climate is moderated by organizational stretch and climate has a direct effect on innovation performance.

We used the approach of Hayes (2015) to test our hypotheses with the mediator climate (M) and the innovation performance $(\mathrm{Y})$ as outcome variables (Table 2). The control variables (industry sector and the number of employees), the independent variable cross-functional collaboration (X), and the moderator variable stretch $(Z)$ were included as fixed effects in each of the two equations predicting $M$ and $Y$. 


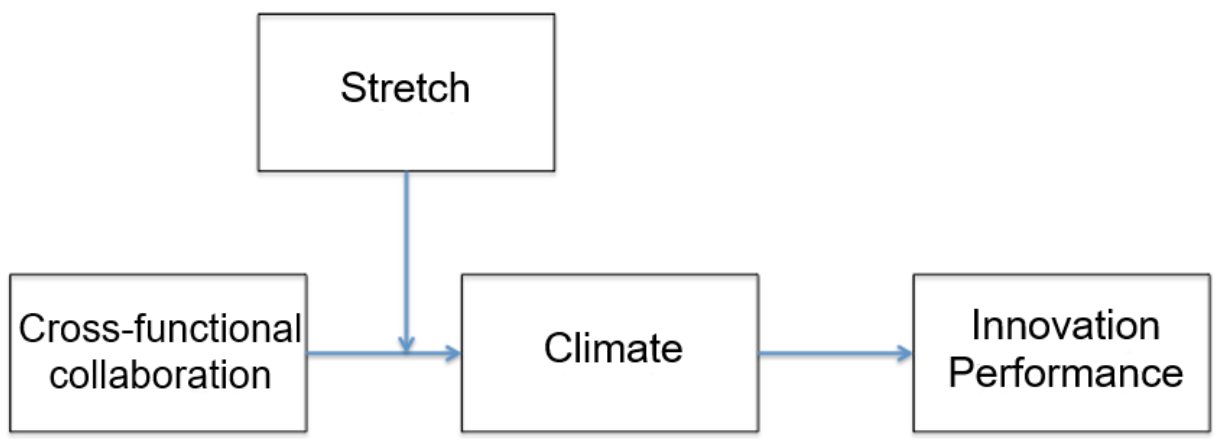

Figure 1. Theoretical model

Table 2. Test of Mediation (Standard Errors in parentheses)

\begin{tabular}{lcccc}
\hline & \multicolumn{2}{c}{ Climate for innovation } & \multicolumn{2}{c}{ Innovation performance } \\
\hline & Coeff. & $95 \% \mathrm{Cl}$ & \multicolumn{1}{c}{ Coeff. } & $95 \% \mathrm{Cl}$ \\
\hline $\begin{array}{l}\text { Cross-functional } \\
\text { collaboration }\end{array}$ & $.302^{* *}(.062)$ & $.181-.424$ & $.199^{*}(.069)$ & $.063-.334$ \\
\hline $\begin{array}{l}\text { Climate for } \\
\text { innovation }\end{array}$ & - & - & $.345^{* *}(.075)$ & $.197-.494$ \\
\hline Stretch & $.439^{* *}(.061)$ & $.318-.561$ & $.051(.073)$ & $-.092-.195$ \\
\hline Industry sector & $.224(.147)$ & $-.065-.513$ & $-.087(.158)$ & $-3.93-.218$ \\
\hline $\begin{array}{l}\text { Number of } \\
\text { employees }\end{array}$ & $.000(.001)$ & $-.0002-.0002$ & $.000(.001)$ & $.000-001$ \\
\hline Constant & $.328(.387)$ & $-.436-1.092$ & $2.72 * *(.408)$ & $1.92-3.52$ \\
\hline & $\mathrm{R}^{2}=.404 ; \mathrm{p}=.000$ & $\mathrm{R}^{2}=.301 ; \mathrm{p}=.000$ \\
$* \mathrm{p}<.01 ; * * \mathrm{p}<.001$ & & &
\end{tabular}

In support of $\mathrm{H} 1$, the effect of cross-functional collaboration on innovation climate is significant and positive (.302) with a $95 \%$ confidence interval excluding zero $(.181-.423)$. In $\mathrm{H} 2$, we predicted that the relationship between cross-functional collaboration and innovation performance is mediated by innovation climate. Consistent with our prediction, we found the mean indirect effect from the bootstrap analysis (by means of bootstrapping of 5.000 repetitions (Zhao et al., 2010) is positive and significant (effect $=.104$ ) with a $95 \%$ confidence interval excluding zero $(.0514-.1804)$. The direct effect between cross-functional collaboration and innovation performance $(.1987)$ is also significant $(p<.05)$. Since, both the indirect effect $(.104)$ and the direct effect (.1987) are significant, and the result of the multiplication of both effects leads to a positive result $(.021)$ it can be concluded that a complementary mediation exist. Thus, hypothesis 2 is supported.

Hypotheses 3 proposed that the relationship between cross-functional collaboration and innovation performance which is mediated through innovation climate is not independent of the moderator stretch. As can be seen in table 3, the interactive effect of cross-functional collaboration and stretch on climate is non-significant as the confidence interval includes zero. However, as stated by Hayes (2015) based on this result, it cannot definitely be claimed that the indirect effect is not moderated by stretch because the interaction effect of cross-functional collaboration and stretch does not quantify the relationship between the moderator and the indirect effect. Therefore, Hayes (2015) recommends a formal test between the relationship of the moderator 
and the size of the indirect effect. The result of this formal test shows that the indirect effect of cross-functional collaboration on innovation performance through climate increases with stretch (see Table 3) as the $95 \%$ bootstrap confidence interval for the moderated mediation index (.027) is between .001 and .062. As this confidence interval does not include zero, and the lower bound is positive, it can be concluded that the indirect effect of cross-functional collaboration on innovation performance through innovation climate is positively moderated by stretch. We plotted this moderated mediation function following Hayes (2015).

Table 2. Table 3: Test of Overall Model

\begin{tabular}{lcccc}
\hline & \multicolumn{2}{c}{ Climate for innovation } & \multicolumn{2}{c}{ Innovation performance } \\
\hline & Coeff. & $95 \% \mathrm{Cl}$ & Coeff. & $95 \% \mathrm{Cl}$ \\
\hline $\begin{array}{l}\text { Cross-functional } \\
\text { collaboration }\end{array}$ & $-.09(.239)$ & $-.56-.381$ & & \\
\hline $\begin{array}{l}\text { Climate for } \\
\text { innovation }\end{array}$ & - & - & $.369^{* *}(.067)$ & $.237-.501$ \\
\hline $\begin{array}{l}\text { Stretch } \\
\text { Cross-functional } \\
\text { collaboration } \times\end{array}$ & $.194(.157)$ & $-.116-.503$ & - & - \\
$\begin{array}{l}\text { Stretch } \\
\text { Industry sector }\end{array}$ & $.246(.146)$ & $-.012-.157$ & - & - \\
\hline $\begin{array}{l}\text { Number of } \\
\text { employees }\end{array}$ & $.000(.001)$ & $-.002-.002$ & $.000(.001)$ & $.000-.003$ \\
\hline Constant & $1.58(.831)$ & $-.06-3.219$ & $2.85(.361)^{* *}$ & $2.138-3.564$ \\
\hline & $\mathrm{R}^{2}=.413 ; \mathrm{p}=.000$ & $\mathrm{R}^{2}=.299 ; \mathrm{p}=.000$ \\
\hline$+\mathrm{p}<.1 ; * * \mathrm{p}<.001$ & & & & $-.096(.154)$ \\
\hline
\end{tabular}

As shown in figure 1, the indirect effect of cross-functional collaboration on innovation performance through innovation climate increases with increasing organizational stretch. Thus, hypothesis 3 is supported.

\section{Discussion}

The starting point of this paper, inspired by contingency theory (Damanpour, 1991; 1996), was our aim to investigate the complex relationship between cross-functional collaboration, organizational stretch, climate for innovation, and innovation performance. Based on this aim, we formulated the research question on how cross-functional collaboration is related to a firm's climate for innovation and innovation performance? To investigate this research question, we collected a random data sample of heads of works councils, resembling cross-departmental middle managers, of 450 large-sized German firms. To the best of our knowledge, this is the first empirical study investigating the relationship between cross-functional collaboration, climate for innovation and innovation performance. Most research in this area has previously considered climate for innovation to exist and to facilitate innovation development and consequently enhance a firm's innovation performance (for example, McLean, 2005; Patterson et al., 2005). Literature, however, suggests that cross-functional collaboration aligns goals among organizational members and facilitates the development of a shared understanding (Crossan et al., 1999; Ernst et al., 2010) which is needed for developing innovations. Hence, we based our three hypotheses on the assumption that cross-functional collaboration fosters the emergence of a climate for innovation.

In support of our hypothesis 1 , we demonstrated (Table 2) that cross-functional collaboration proved to be a predictor of climate for innovation. This finding suggests that climate for innovation can be stimulated via organizational factors, as for example, the composition of cross-functional new product development or innovation teams. Furthermore, we could confirm hypothesis 2 of our study that the effect of cross-functional collaboration on innovation performance is mediated by the firm's climate for innovation 


\section{Indirect effect of cross-functional collaboration on Innovation performance through climate for innovation.}

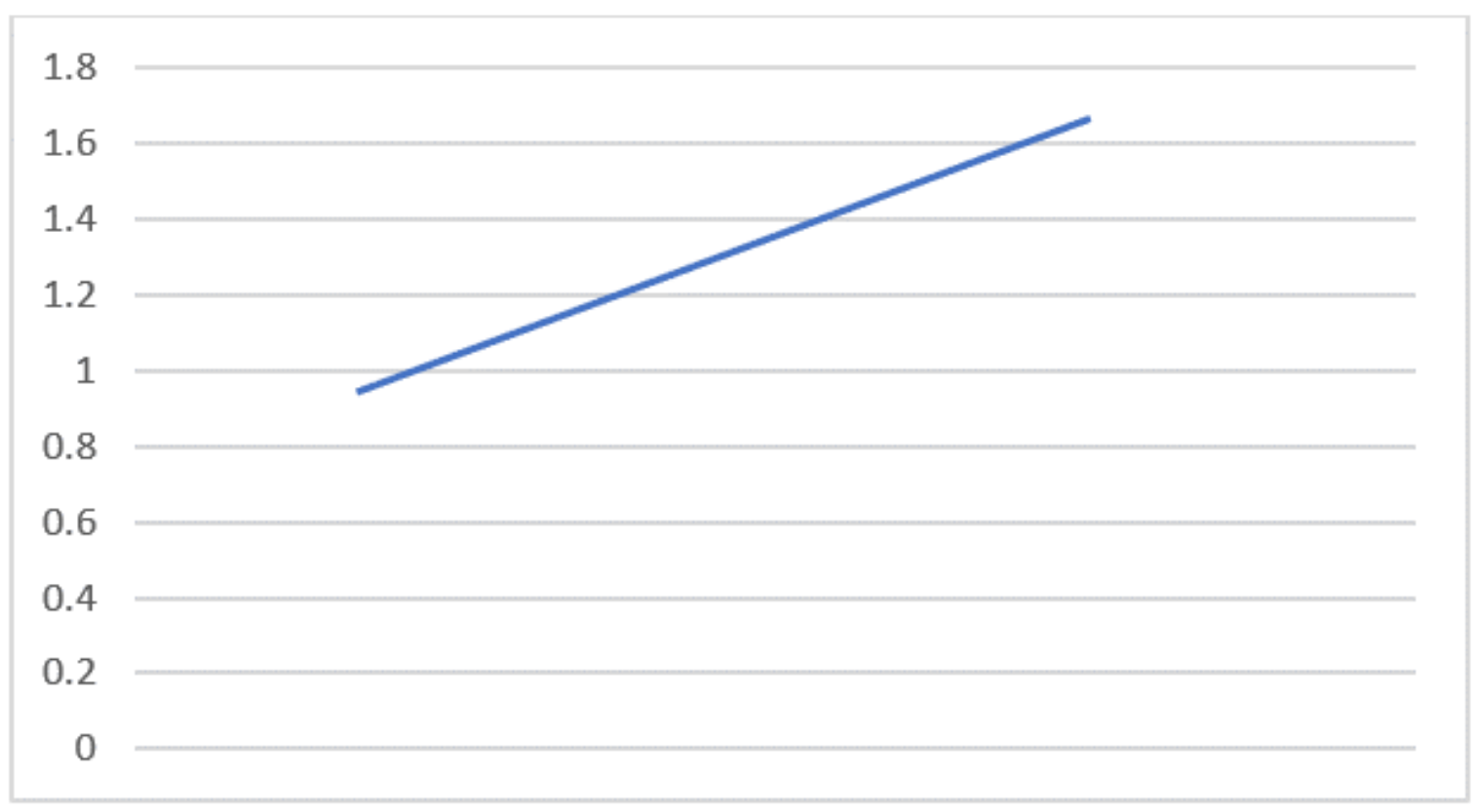

Figure 2. Visualization of the moderated mediation linear function

(Table 2). If organizational factors as team composition are suitable, it may be possible to foster climate for innovation by selecting organizational members with a high willingness to collaborate with diverse other organizational members.

However, facilitating cross-functional collaboration might be valuable to foster an organizational climate for innovation but as our study highlights combining it with organizational stretch (hypothesis 3 ) leads to a higher level of climate for innovation and consequently higher innovation performance (Table 3). Specifically, our results showed that stretch is a complementary asset with which a firm's climate for innovation is further stimulated. Although manifold forms of a stretch have been investigated in prior innovation studies, ambitious innovation goals, explicit performance parameters, and further quality parameters as for example reduced production and resource cost seem to be the most important ones (McLean, 2005; Seijts, \& Latham, 2005). Following contingency theory (Damanpour, 1991; 1996), as our starting point, each firm must find a specific balance of 'soft' and 'hard' factors influencing its organizational innovation climate.

In addition, the findings of our study are in line with the results of the work of Belassi et al. (2007). They found that firms with financially successful new product development projects support an organizational culture that "encourages employees to exert maximal effort, and that makes them comfortable in dealing with unfamiliar situations and in expressing their opinions, even when in disagreement with supervisors or managers" (p. 19). Furthermore, the contributions of this paper point into the same direction as the finding of Patterson et al. (2005) that "subsequent productivity (collected one year after the climate survey)" (p. 398) was significantly correlated with organizational climate. The results of our study also show similarity to the recent finding of Somech and Drach-Zahavy (2013) that team creativity only translates to innovation implementation under high levels of climate for innovation.

From a theoretical point of view, the paper helps to clarify the importance of the role of organizational innovation climate for firms' innovation performance in the complex relationship between cross-functional collaboration, stretch and innovation performance (Belassi et al., 2007; Evanschitzky et al., 2012, Zuefle et al., 2021). Furthermore, our findings confirm that organizational innovation climate is only one necessary building block for the explanation of firms' innovation performance. This building block needs to be balanced by the top and middle managers with further building blocks such as stretch on the one hand and cross-functional collaboration as an enabler of knowledge transfer between firms' different departments 
on the other (for example, Belassi et al., 2007). Our finding regarding the important role of middle managers for the innovation climate and performance of the investigated firms (Pries, 2006; Jirjahn, 2010; Skorupińska-Cieślak, 2019; Müller \& Neuschäffer, 2020) is in line with the result of the meta-analysis of Damanpour (1991, p. 581) that particularly organizational members at the 'middle level' are affected by a supportive innovation climate.

\section{Conclusions}

The basic idea of this article was the exploration of the complex interaction between cross-functional collaboration, climate for innovation and firms' innovation performance. Our study focused on heads of works councils perception, which have a key role in developing innovations in German companies (Addison et al., 2017; Bosch \& Schmitz-Kießler, 2020; Kraft \& Lammers, 2019). The results of the study contribute in three ways to the literature on innovation management and workplace codetermination. First, it shows that the effect of cross-functional collaboration on innovation climate is significant and positive. Second, the results confirm that the relationship between cross-functional collaboration and innovation performance is complementarily mediated by innovation climate. Third, the investigation shows that the indirect effect of cross-functional collaboration on innovation performance through innovation climate increases with increasing organizational stretch. More in detail, our findings demonstrate that stretch is a complementary asset, which further stimulates a supportive climate for innovation.

Based on our assessment of the literature, we can conclude that these empirical results of our study are still relevant and novel (e.g., Genz et al., 2019; Kraft \& Lammers, 2019). Referring to these novel findings, we can draw some important managerial conclusions. First, firms should balance 'soft' factors as cross-functional collaboration and 'hard' factors as stretch in order to stimulate a productive innovation climate. Companies can manage this balancing act, for example, by applying demanding and effective incentive systems for their employees. Second, both expert employees and middle managers from different departments should be systematically involved in cross-functional collaboration. Third, the findings of our study indicate that companies, which succeed in this balancing act, also have higher chances for a considerable increase in their innovation performance. However, the present study also has limitations that reveal possible avenues for further research. Our sample is based on a relatively small group of cross-departmental middle managers (heads of work's councils) of German firms, which may limit the generalizability of our findings. A comparison of our sample with those of other studies suggests, however, the representativeness of our sample. Furthermore, we conducted our empirical study in randomly selected firms and controlled for industry and the number of employees. Therefore, we cannot rule out any effects based on company differences, but the following studies should carefully consider to replicate our study in a single firm to receive a deeper understanding of this complex relationship between cross-functional collaboration, climate for innovation and innovation performance. Our data regarding climate for innovation were self-reported. This issue does not differ from previous studies (e.g., Somech \& Drach-Zahavy, 2013); although, in our data collection we followed suggestions provided in the literature (e.g., Podsakoff, et al., 2003) to minimize common method variance. Finally, we collected our data before the covid pandemic reached Germany. Therefore, we cannot rule out any effects which the pandemic might have on the complex relationship between cross-functional collaboration and innovation performance.

\section{References}

Ashforth, B.E. (1985). Climate Formation: Issues and Extension. The Academy of Management Review, 10(4), 837-847.

Atuahene-Gima, K., \& Murray, J. Y. (2007). Exploratory and Exploitative Learning in New Product Development: A Social Capital Perspective on New Technology Ventures in China. Journal of International Marketing, 15(2), 1-29.

Baer, M., \& Frese, M. (2003). Innovation is not enough: Climates for initiative and psychological safety, process innovations, and firm performance. Journal of Organizational Behavior, 24(1), 45-68.

http://www.open-jim.org

http://creativecommons.org/licenses/by/3.0 
Belassi, W., Kondra, A. Z., \& Tukel, O. I. (2007). New Product Development Projects: The Effects of Organizational Culture. Project Management Journal, 38(4), 12-24.

Berlemann, M., \& Jahn V. (2014). Governance, Firm Size and Innovative Capacity: Regional Empirical Evidence for Germany. Helmut Schmidt University Hamburg, Department of Economics, Working Paper No. 150, Hamburg.

Bertels, H. M. J., Kleinschmidt, E. J., \& Koen, P. A. (2011). Communities of Practice versus Organizational Climate: Which One Matters More to Dispersed Collaboration in the Front End of Innovation? Journal of Product Innovation Management, 28(5), 757-772.

Genz, S., Bellmann, L., \& Matthes, B. (2019). Do German Works Councils Counter or Foster the Implementation of Digital Technologies? First Evidence from the IAB-Establishment Panel. Journal of Economics and Statistics, 239(3), 523-564.

Bosch, G., \& Schmitz-Kießler, J. (2020). Shaping Industry 4.0 - an experimental approach developed by German trade unions. Transfer: European Review of Labour and Research, 26(2), 189-206.

Crossan, M.M., Lane, H.W., \& White, R.E. (1999). An Organizational Learning Framework: From Intuition to Institution. Academy of Management Review, 24(3), 522-537.

Damanpour, F. (1991). Organizational Innovation: A Meta-Analysis of Effects of Determinants and Moderators. Academy of Management Journal, 34(3), 555-590.

Damanpour, F. (1996). Organizational Complexity and Innovation: Developing and Testing Multiple Contingency Models. Management Science, 42(5), 693-716.

de Luca, L. M., \& Atuahene-Gima, K. (2007). Market Knowledge Dimensions and Cross-Functional Collaboration - Examining the Different Routes to Product Innovation Performance. Journal of Marketing, $71(1), 95-112$.

de Vasconcelos Gomes, L.A., Figueiredo Facin, A. L., \& Hourneaux, F. (2019). Building a bridge between performance management, radical innovation, and innovation networks: A systematic literature review. Creativity and Innovation Management, 28(4), 536-549.

Denison, R. D. (1990). Corporate Culture and Organizational Effectiveness. John Wiley, New York.

Ernst, H., Hoyer, W.D., \& Rübsaamen, C. (2010). Sales, Marketing and R\&D Cooperation Across New Product Development Stages - Implications for Success. Journal of Marketing, 74(5), 80-92.

Evanschitzky, H., Eisend, M., Calantone, R. J., \& Jiang, Y. (2012). Success Factors of Product Innovation: An Updated Meta-Analysis. Journal of Product Innovation Management, 29(S1), 21-37.

Ghoshal, S., \& Bartlett, C. A. (1994). Linking organizational context and managerial action: The dimensions of quality of management. Strategic Management Journal, 15(S2), 91-112.

Gibson, C. B., \& Birkinshaw, J. (2004). The Antecedents, Consequences, and Mediating Role of Organizational Ambidexterity. Academy of Management Journal, 47(2), 209-226.

Gumbrell-McCormick, R., \& Hyman, R. (2010). Works councils: the European model of industrial democracy? In: Wilkinson, A., Gollan, P.J., Marchington, M. and Lewin, D. (eds.)', The Oxford Handbook of Participation in Organizations, Oxford Handbooks in Business and Management. Oxford: Oxford University Press, 286-314.

González-Romá, V., Peiró, J.M., \& Tordera, N. (2002). An Examination of the Antecedents and Moderator Influences of Climate Strength. Journal of Applied Psychology, 87(3), 465-73.

Hayes, A.F. (2015). An Index and Test of Linear Moderated Mediation. Multivariate Behavioral Research, $50(1), 1-22$.

Jasmand, C. Blazevic, V., \& de Ruyter, K. (2012). Generating Sales While Providing Service: A Study of Customer Service Representatives' Ambidextrous Behavior. Journal of Marketing, 76(1), 20-37.

Jirjahn U. (2010). Works councils and employment growth in German establishments. Journal of Economics, 34(3), 475-500. 
Addison, J. T., Teixeira, P., Evers, K., \& Bellmann, L. (2017). Collective Bargaining and Innovation in Germany: A Case of Cooperative Industrial Relations? Industrial Relations A Journal of Economy and Society, 56(1), 73-121.

Johnston, H. (2020). Labour geographies of the platform economy: Understanding collective organizing strategies in the context of digitally mediated work. International Labour Review, 159(1), 25-245.

Klein, K.J., Conn, A.B., Smith, D.B., \& Sorra, J.S. (2001). Is everyone in agreement? An Exploration of within-group Agreement in Employee Perceptions of the Work Environment. Journal of Applied Psychology, 86(1), 3-16.

Kraft, K., \& Lammers, A. (2019). Employee Representation and Innovation - Disentangling the effect of legal and voluntary representation institutions in Germany. Discussion Paper Nr. 4/2019, SFB 823, Dortmund. Retrieved 20 April 2021, from https://d-nb.info/1178792838/34

Kuhlenkötter, B., Lins, D., Niewerth, C., Prinz, C., Schäfer, M., \& Wannöffel, M. (2020). Co-determination and participation in the transformation towards Industry 4.0. Arbeit, 28(4), 401-422.

McLean, L. (2005). Organizational Culture's Influence on Creativity and Innovation: A Review of the Literature and Implications for Human Resource Development. Advances in Developing Human Resources, $7(2), 226-246$.

Müller-Jentsch, W. (1995). Germany: From Collective Voice to Co-management. In: Joel Rogers and Wolfgang Streeck (eds.), Works Councils, Consultation, Representation, and Cooperation in In-dustrial Relations. Chicago and London: University of Chicago Press, 53-78.

Müller-Jentsch W. (1998). Betriebsräte-Befragung und Analyse der Industriepolitik im Maschinen- und Anlagenbau. Auszüge des Abschlussberichts an die Deutsche Forschungsgemeinschaft „Mo-dernisierung von Arbeitssystemen und industriellen Beziehungen im Maschinenbau". Bochum.

Müller, S., \& Neuschäffer, G. (2020). Worker participation in decision-making, worker sorting, and firm performance, IWH Discussion Papers, No. 11/2020, Leibniz-Institut für Wirtschaftsforschung Halle (IWH), Halle (Saale). Retrieved 20 April 2021, from https://www.iwh-halle.de/en/publications/detail/ worker-participation-in-decision-making-worker-sorting-and-firm-performance/

Nienhüser, W. (2020). "Works councils". In Handbook of Research on Employee Voice. Cheltenham, UK: Edward Elgar Publishing.259-276.

Patterson, M. G., West, M. A., Shackleton, V. J., Dawson, J. F., Lawthom, R., Maitlis, S., Robinson, D. L., \& Wallace, A. M. (2005). Validating the organizational climate measure: links to managerial practices, productivity and innovation. Journal of Organizational Behavior, 26(4), 379-408.

Podsakoff, P. M., MacKenzie, S. B., Lee, J.-Y., \& Podsakoff, N. P. (2003). Common method bias in behavioral research: A critical review of the literature and recommended remedies. Journal of Applied Psychology, 88(5), 879-903.

Preacher, K.J., Rucker, D.D., \& Hayes, A.F. (2007). Addressing Moderated Mediation Hypotheses: Theory, Methods, and Perceptions. Multivariate Behavioral Research, 42(1), 185-227.

Pries, L. (2006). Cost competition or innovation competition? Lessons from the case of the BMW plant location in Leipzig, Germany, Transfer. European Review of Labour and Research, 12(1), 11-29.

Roberson, Q.M. (2006). Justice in Teams: The Activation and Role of Sensemaking in the Emergence of Justice Climates. Organizational Behavior and Human Decision Processes, 100(2), 177-192.

Roy, I., Cantner, U., \& Gerstlberger, W. (2020). Works Councils, Training Activities and Innovation: A Study of German Firms. International Journal of Human Resources Development and Management, 20(3/4), 269-294.

Scott, S. B., \& R.A. (1994). Determinants of Innovative Behavior - A Path Model of Individual Innovation in the Workplace. Academy of Management Journal, 37(3), 580-607.

Seijts, G. H., \& Latham, G. P. (2005). Learning versus Performance Goals: When Should Each Be Used? 
The Academy of Management Executive, 19(1), 124-131.

Skorupińska-Cieślak, K. (2019). What determines the role and position of works councils? Models of councils in Polish organizations. Economic and Industrial Democracy, 1.-26.

Somech, A., \& Drach-Zahavy, A. (2013). Translating team creativity to innovation implementation: The role of team composition and climate for innovation. Journal of Management, 39(3), 684-708.

Song, X. M., \& Perry, M. E. (1997). A Cross-National Comparative Study of New Product Development Process - Japan and the United States. Journal of Marketing, 61(2), 1-18.

Song, X., Montoya-Weiss, M.M., \& Schmidt J.B. (1997). Antecedents and Consequences of CrossFunctional Cooperation: A Comparison of R\&D, Manufacturing, and Marketing Perspectives. Journal of Product Innovation Management, 14(1), 35-47.

Tsai, K.-H. \& Hsu, T.T. (2014). Cross-Functional collaboration, competitive intensity, knowledge integration mechanisms, and new product performance: A mediated moderation model. Industrial Marketing Management, 43(2), 293-303.

Weick, K., \& Roberts, K. (1993). Collective mind and Organizational Reliability: The Case of Flight Operations in an Aircraft Carrier Deck. Administrative Science Quarterly, 38(3), 357-381.

Whittall, M., \& Trinczek, R. (2019). "Plant-Level Employee Representation in Germany: Is the German Works Council a Management Stooge or the Representative Voice of the Workforce?". In International Comparative Employee Relations. Cheltenham, UK: Edward Elgar Publishing. 119-132.

Zhao, X., Lunch Jr., J. G., \& Chen, Q. (2010). Reconsidering Baron and Kenny: Myths and Truths About Mediation Analysis. Journal of Consumer Research, 37(2), 197-206.

Zohar, D., \& Tenne-Gazit, O. (2008). Transformational Leadership and Group Interaction as Climate Antecedents: A Social Network Analysis. Journal of Applied Psychology, 93(4), 744-757.

Zuefle, M., Rennpferdt, C., \& Krause, D. (2021). Cross-departmental and cross-disciplinary product development - An industry survey on the necessity and future development of cross-departmental and cross-disciplinary perspectives. Procedia CIRP, 100, 625-630. 


\section{Biographies}

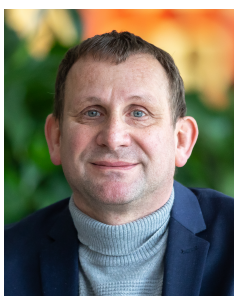

Wolfgang Gerstlberger. Wolfgang Gerstlberger, Ph.D. is a Professor for Operations Management at the Department of Business Administration, School of Business and Governance, of Tallinn University of Technology (TalTech). He gained his PhD in Social Sciences and his Habilitation for Business Administration from Kassel University in Germany. Wolfgang has more than 20 years of experience in research, teaching and (inter-) national consultancy projects. He also coordinated and participated in several national and European research projects dealing with different kinds of innovation, transformation and digitalization processes in the public and private sector. His main research interests are in sustainable supply chain management, innovation and operations management, digital transformation of businesses, and innovation systems on different levels.

CRediT Statement: Conceptualization, Methodology, Writing ? Original draft preparation, Investigation, Formal analysis. .

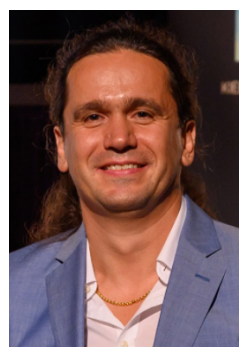

Alex da Mota Pedrosa. Alex da Mota Pedrosa joined the Fachhochschule für Verwaltung und Dienstleistung in September 2020 as Professor in processmanagement and digitalization in public administration. Previously, he several roles in the area of innovation management and digitalization at the DHSH, Germany and University of Southern Denmark, Denmark. Alex's teaching encompasses lectures and seminars on topics such as digitale transformation in the public sector, innovation management, business modes, and open innovation. He currently teaches on the undergraduate and executive programs at Fachhochschule für Verwaltung und Dienstleistung. Alex's research revolves around the digital transformation and innovation management. In this, context, he particularly focuses on the role of employees, a topic which is of high interest and relevance to academics and practitioners alike. He has published in journals such as Creativity and Innovation Management, International Journal of Technology, Internatinonla Journal of Business Innovation and Research, Internatinal Journal of Physical Distribution and Logistics Management.

CRediT Statement: Conceptualization, Methodology, Writing ? Original draft preparation, Investigation, Formal analysis, Data curation, Visualization.. 